\title{
Ultrasound Semeiotics of Lymphatic Modifications in the Lower Limbs.
}

\author{
F Passariello ${ }^{1}, \mathbf{R}$ Carbone $^{1}$, A Mancini $^{1}$ \\ ${ }^{1}$ Società Italiana Operatori C.H.I.V.A. - Sede Napoli 02, Centro Diagnostico AQUARIUS, via Francesco Cilea, 280 - \\ 80127 Napoli tel./fax 0039-081714110
}

presented to: Giornate Nazionali di Angiologia 1991. Milano, 23-29 giugno, 1991

submitted: Apr 9, 2017, accepted: Apr 9, 2017, EPub Ahead of Print: Apr 28, 2017, published: May 1, 2017

Conflict of interest: None

DOI: 10.24019/jtavr.17 - Corresponding author: Dr. Fausto Passariello, afunzionale@tiscalinet.it,

(C) 2016 Fondazione Vasculab impresa sociale ONLUS. All rights reserved.

\author{
Abstract Reprint of a conference paper on ultrasound \\ investigation in lymphedema.
}

Keywords Lymphopathies, Subcutaneous tissue, Ultrasound, Lympatic lakes, Phlebo-lymphedema

\section{Foreword}

Ultrasound investigation of the venous system of the lower limbs allows the coincidental observation of modifications that may be of a lymphatic origin.

In single patients a complete overlap of lymphatic and venous pathologies is never found in all areas. One zone may be affected by the lymph pathology, while another may be intact.

In the same way, venous insufficiency does not involve all the large veins of the various districts to the same extent. Indeed, venous and lymphatic components appear with different intensities and in different areas of the lower limb.

When the two pathologies overlap, their characteristic signs may manifest several variations. Or, on the contrary, these signs may be present independently: for example, in patients without phlebopathy and with evident cutaneous and sub-cutaneous modifications.

The detection of the same ultrasound signs in the phlebopathic patient leads us to diagnose a connection with a lymphatic pathology.

In our sample there is a clear preponderance of venous or mixed lymphatic-venous pathology. The division of the symptoms by area and into the small number of pure lymphatic pathologies allowed us make a theoretical formulation of the Semeiotics of Lymphatic Modifications.

\section{Normal and pathologic ultrasound anatomy}

Normal appearance is considerably influenced by the device resolution and the probe emission frequency.

\section{Skin, Subcutaneous layer and adipose tissue}

Generally, it is possible to visualize the superficial hyper-echogenic layer, constituted by the epidermis and by the underlying derma (slightly less echogenic), which can be differentiated from the subcutaneous layer, which is comparatively less echogenic.

The subcutaneous layer is homogenous and transmits the US freely, with negligible reflection, allowing visualization of the underlying structures.

In some patients, instead, it is dense and inhomogeneous, with internal hyper-reflecting zones, separated by thin trabeculae, with mesh arrangement and an appearance comparable to the clumps of dry desert ground, of cracked stones, with countless fissures, almost like a clay desert.

This subcutaneous and suprafascial image produces poor quality visualization of deep structures and is present together with wider areas which appear as fissures or surfaces which are approximately parallel to the underlying fascia, even when cross-sectioned in any given direction. 


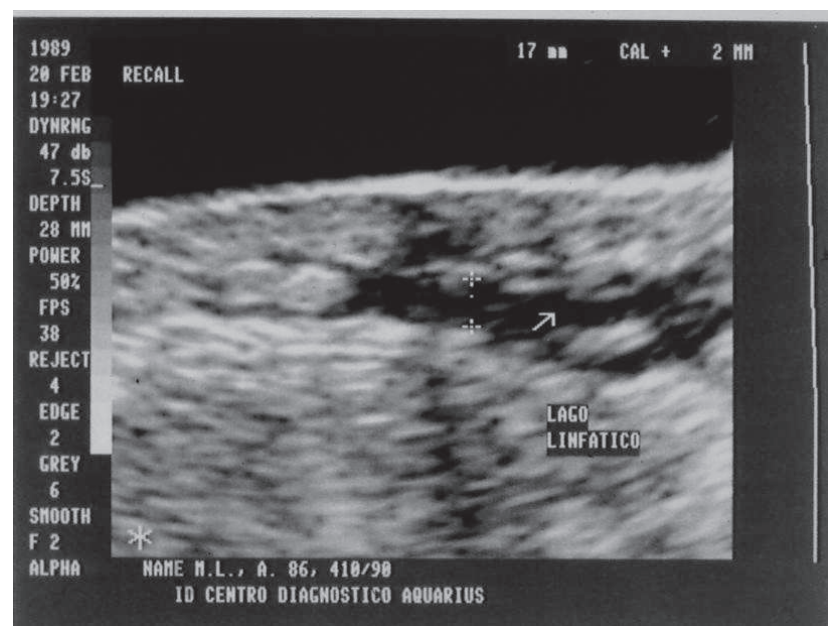

Figure 1 - A lymphatic lake.

They appear in a suprafascial position, with a low thickness completely anechogenic area, i.e. like a thick tissue only in several points, like an optical lens which is thin at the margins: layer or lymphatic lake. (Fig. 1)

A third element is the hyper-reflectiveity of the epidermis, which projects shadows into the shape made up of fine rectilinear lines, with a reduction in the quality of the image.

In very old patients this may be an expression of dryness and dehydration of the skin, as also in lymphopathologies, where a higher protein concentration is accompanied by a percent reduction of the hydric content.

\section{Fascia, tendons and muscles}

In deep layers, one encounters the hyper-echogenic fascia, that wraps the muscle mass and separates it individually through its septa, that form the deep muscular lodgings.

The anatomy of the single muscles of the limb is not of interest here, but rather their visibility, especially for those near the surface, because we may evaluate subcutaneous sclerosis based on the good visibility of the deep structures.

The tendons are quite dense fibrous connecting tissue and, therefore, are barely subject to variations in hydric content. An interest in their observation lies mainly in their greater stability, permitting identification of a reference point for investigations over time

\section{Lymphnodes}

The lymphatic vessels are not visible, but only the lymphnodes, even those of normal volume and structure.

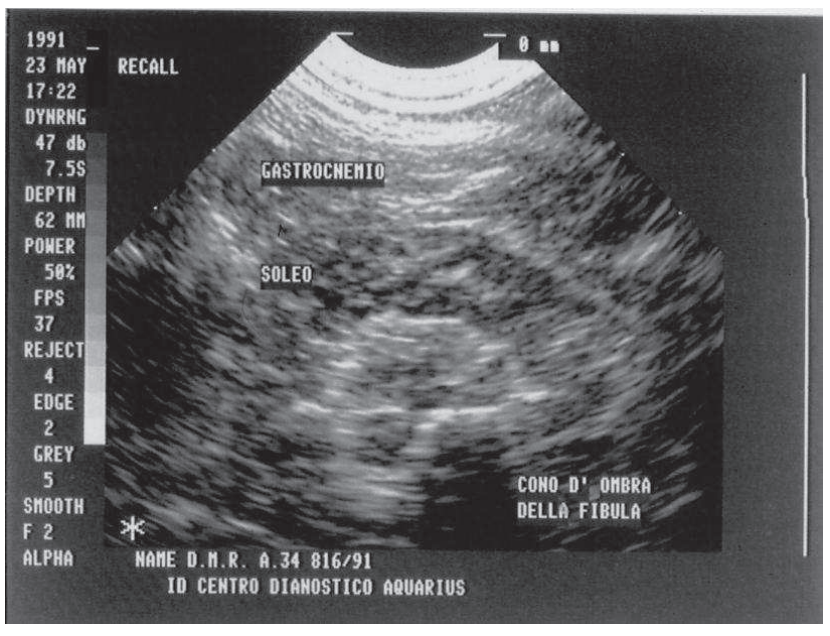

Figure 2 - Cross section of the normal calf. Subcutaneous tissue, muscles, fascia, bones.

On ultrasound examination one may easily identify them through their quite typical structure: a hyperechogenic capsule, an hypo-anechogenic ring and a central zone of intermediate echogenicity. The volume is quite variable instead.

The inguinal stations are found near the confluences of the saphenous arch and distributed in groups. The nodes positioned cranially to the inguinal nodes (intra-abdominal for example) are more difficult to observe because they are masked by intestinal gas. Besides, routine examination does not entail their identification. They are generally observable in deep intra-abdominal, para-aortic and paravertebral sites.

There is no typical alteration for lymphnodes in lymphopathologies of the lower limb. The only easily identifiable aspect is the increase in volume, up to palpability, that also includes an increase in the number of visible lymphnodes at examination.

In many subjects these are generally situated in the groin, with a frequency hardly altered by anti-infective therapy, that is, in a zone quite distant from the typical lymphatic cutaneous lesions, that reach down to below the knee.

In general a lymphatic edema is rhizomelic. This would be an unfavourable point for our observations, that should be limited just to alterations of a non-venous origin. In our experience lymphatic edema appears proximally isolated, while cutaneous lesions are distal and associated to the edema.

Regarding volumetric increase, it must be given importance to interdigital lesions of various origins, especially mycotic ones.

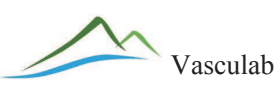




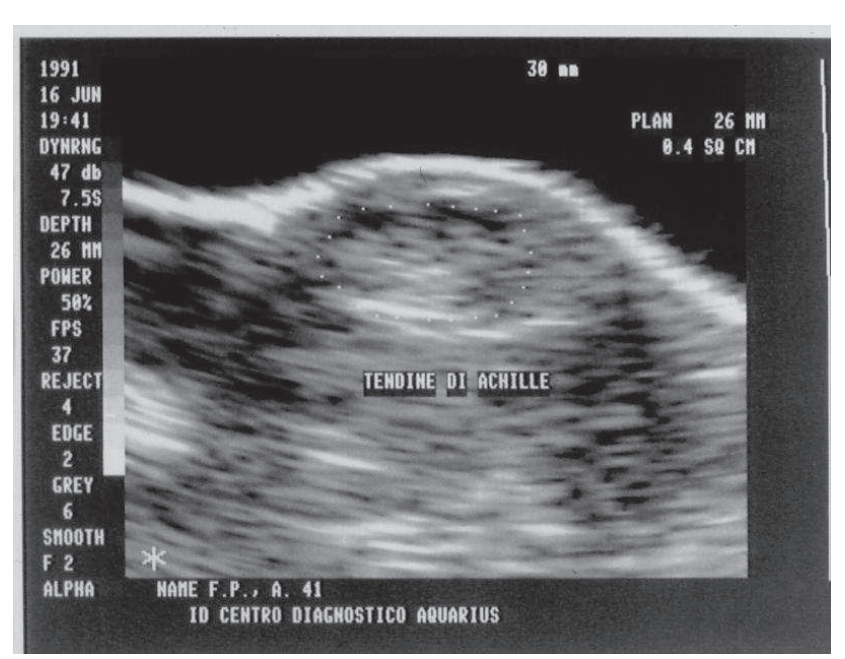

Figure 3 - Reflectivity of fibrous structures (Achille's tendon) as a reference for echogenicity.

\section{Lymphatic-venous intersection}

The presence of venous alterations in a district is clearly identifiable, when an insufficient venous vessel transits the zone, even more so if there are also insufficient large perforating or re-entry vessels.

The coexistence of lymphopathy in the zone may create mixed images of phlebo-lymphopathy.

The above observations characterize the stages of initial pathology, that later lead to the same final appearance.

As with a river that receives many tributaries, it is not possible to identify the origins of the single masses of water, so, even when a cutaneous or subcutaneous alteration is already established it is not possible to distinguish its origin.

An exception can be made for the echographic observation of a perforating vessel that leads to a lymphatic lake, because it shows a clear connection between the two pathologies. It is the index of a mixed form, that cannot exist in just pure forms. It is the sign of a net intersection of the symptoms, that are not only co-present in the same district but that have also influenced each other.

However, it is yet to be demonstrated that there has been a flow of material. The aspect is that of a closed cavity connected with a venous vessel, completely analogous to false arterial aneurism. In the venous symptomology, however, there is no pulsation, because the venous pressure is minimal and barely pulsating.

If the lymphatic lake increases in dimensions it does so over very long period of months or years.

The confluence of the lymphatic and venous spaces places a real doubt on the natural history of the echographic images of the illness. This history cannot be rebuilt through

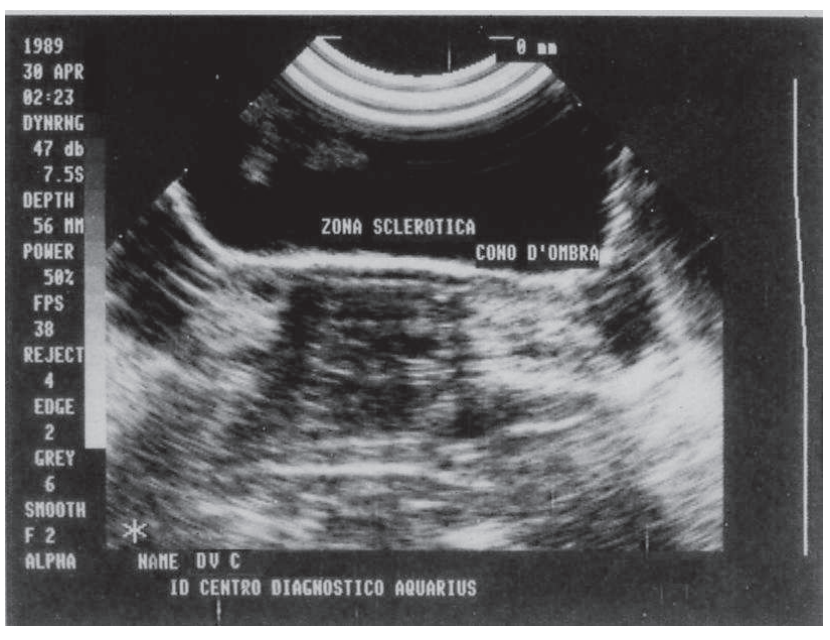

Figure 4 - Sclerotic layers (as in an ulcer) increase reflectivity, thus reducing visibility of deep structures.

echography because the observations are not numerous enough.

One may only formulate informed hypotheses:

- $\quad 1$. The perforating vessel provokes expansion of the tissues with the creation of the lymphatic lake. Normally the perforating vessels do not end in the subcutaneous layer, but in a surface vessel. The dislocation of the subcute with the appearance of fissures and breaks, and not simple movement of tissue, could be determined by the ebb and flow of the blood in the perforating vessel. The breakage of tissue could also generate the laceration of a vessel and, therefore, the lympho-venous connection.

2. The lymphatic lake is so highly stressed that it finds release in a venous vessel, determining a lympho-venous compensatory anastomosis.

3. The two aspects are the consequence of an unknown common cause.

\section{Conclusions}

The sum of the observations of echographic semeiotics shown here is the fruit of work experience maturing at the Centro Diagnostico Aquarius in the course of venous diagnostic examinations carried out for the CHIVA treatment of venous insufficiency in the lower limbs.

No criterion other than the clinical criterion was used for the qualification of lymphatic edema. Obviously, more accurate observations could derive from a comparison between ultrasound and another well-established method for the study of lymphopathologies. 


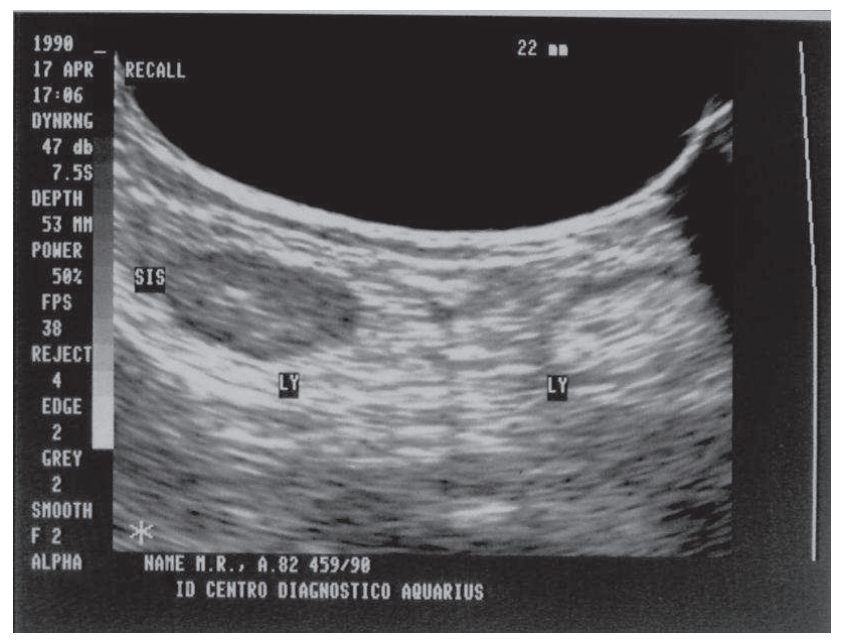

Figure 5 - Superficial lymphnodes (groin) are a common anatomical finding.

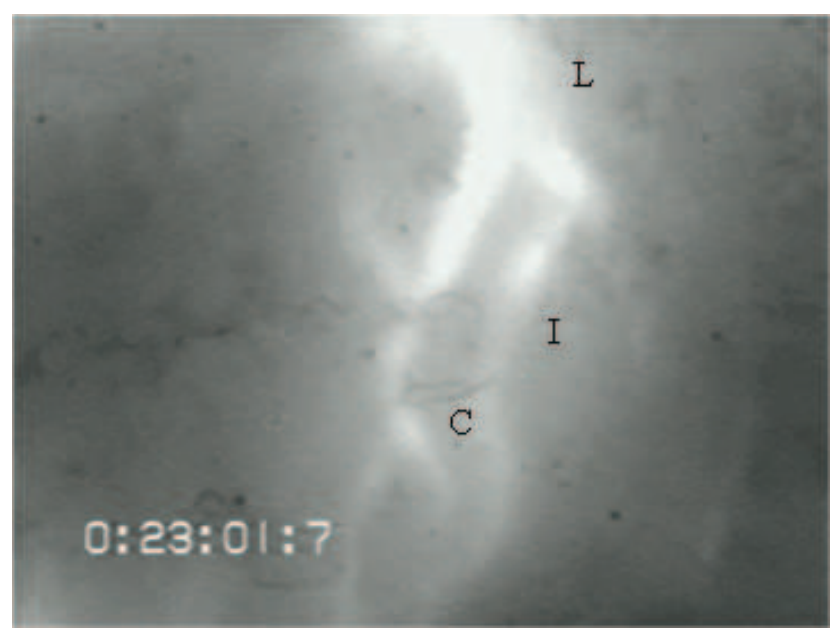

Figure 7 - Fluorescent Microlimphography. Microcirculatory Unit. L - lymphatic microvessel. I interstitial tissue. C - blood capillary. Unpublished image, courtesy of C Allegra.

Some observations are necessary:

- $\quad$ Echographic examination is not able to directly evaluate the lymphatic circulation, but only the final, anatomical and functional, consequences of alterations that have already been present for some time.

- This does not mean that it cannot identify alterations that only involve some districts in the initial phase.

- $\quad$ Echographic examination allows non-invasive long-term monitoring of pharmacological or surgical treatment of lymphopathologies.

In order to allow a comparison of echographic images obtained from the same patient at a considerable distance

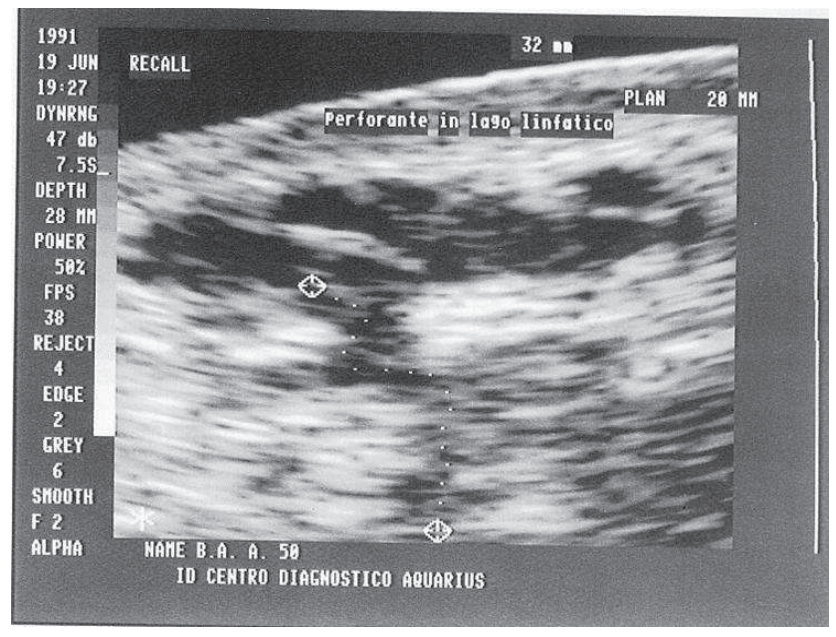

Figure 6 - The uncommon connection between a perforating vein and a lymphatic lake.

of time, the Centro Diagnostico Aquarius is carrying out research on the automatic quantification of echographic images. This argument shall be fully treated in another work.

\section{Notes to the reprint}

This is the translation from Italian into English of an originary conference paper to the "Giornate Nazionali di Angiologia 1991. Milano, 23-29 giugno, 1991"1.

It is the $1^{\text {st }}$ detailed paper presented in Italy about ultrasound of soft tissues in lymph diseases.

It is not an absolute innovation because several signs were already reported in a 1986 book of C Franceschi et al. ${ }^{2}$ and here reported methods were already practiced in 1987 at the Centre d'explorations medicales, Av. de Wagram, Paris of C Franceschi.

Later, this knowledge was quickly spread, nevertheless without citing the source nor acknowledging the priority of the French School.

The current reprint tries in some way to fill this gap.

The previous paper included only one picture and no references, while bibliography is added here instead, together with several images of the original presentation (Figures 2 - 6).

During the presentation in Milan, there was in the audience also Prof. Marceau Servelle $(\dagger$ 2002), who communicated to the Authors his favourable comments, hoping for an additional in-depth analysis of several treated topics.

The original paper was the start of a succession of research works in the following years at the Centro 
Diagnostico Aquarius, Napoli (Italia), representing the basic precondition of them.

A last remark deals with the hypothesis of the connection between the venous system and a lymphatic lake through a perforating vein.

It is an anecdotal remark, of whom nowadays only a few ultrasound images can be provided (Fig 6). Thus, the phenomenon is uncommon and not much studied and it matches the concept of phlebolymphedema, resumed later by Cavezzi and Michelini ${ }^{3,4}$, but already stated (not with

\section{References}

1) Passariello F, Carbone R, Mancini A. Semeiotica Ultrasuonografica delle alterazioni linfatiche nell'arto inferiore [Ultrasound Semeiotics of Lymphatic Modifications in the Lower Limbs]. Proceedings of "Giornate Nazionali di Angiologia 1991. Milano, 23-29 giugno". Minerva Angiologica. Aprile Giugno 1991; 16(Suppl. 1 al N. 2):453-7.

2) Franceschi C, Franco G, Luizy F, Tanitte M Précis d'échotomographie vasculaire. [A Primer of Vascular Echotomography] Paris, Éditions Vigot, 1986, p. 256-7.

3) Cavezzi A., Michelini S. Il Flebolinfedema, dalla diagnosi alla terapia. [Phlebo-lymphoedema: from diagnosis to therapy] Ed. Auxilia, Bologna 1997.

4) Cavezzi A, Michelini S. Phlebolymphoedema, from diagnosis to therapy. Ed. PR Communications, Bologna 1998, ISBN 88-900300-1-1.

5) Van der Molen HR. Über die chronische venöse Insuffizienz. Verhandlungen der Deutschen Gesellschaft für Venenerkrankungen. Schattauer, Stuttgart 1957, p. 41-59.

6) Haid H, Lofferer O, Mostbeck A, Partsch H. [Lymph kinetics in the postthrombotic syndrome under compression bandages. Med Klin. 1968. May 10;63(19): 754-7]

7) Proceeding of the 3rd International Congress of Phlebology in Amsterdam 1968 (Ed HR van der Molen, J. van Limborgh, W. Boersma, Édition Stenvert Zoon, Apeldoorn, NL) the same term) in several, experimental but not ultrasound based, previous studies ${ }^{5-13}$ (Fig 7).

\section{Acknowledgements}

A spontaneous Vasculab discussion in 2011 afforded the theme of phlebolymphedema ${ }^{14}$. We thank all the participants for their contribution and especially for their active role: C Allegra, M Andrade, PL Antignani, J Armer, A Bollinger, A Caggiati, C Campisi, L Corcos, A Džupina, D Eckert, J Ferreira, E Foeldi, I Forner-Cordero, C Franceschi, M Hirai, BB Lee, N Morrison, WL Olszewski, J Opie, H Partsch, E Pasqual, F Passariello, A Pieri, AA Ramelet, H Rieger, M Simka, E Stephen, N Theivacumar, AM Vaillant-Newman, RA Weiss, J Wigg.

8) Battezzati M, Donini I. Il Sistema Linfatico nella pratica clinica. [The lymphatic system in clinical practice] 1967. Piccin Ed., Padova, Italia.

9) Bollinger A, Isenring G, Franzeck UK. Lymphatic microangiopathy: a complication of severe chronic venous incompetence (CVI). Lymphology 1982 Jun;15(2):60-5.

10) Bollinger A, Partsch H, Wolfe JHN (eds.). The initial lymphatics, new methods and findings. Thieme-Stratton Inc., Stuttgart New York, 1985.

11) Haid H. Venenerkrankungen, $5^{\text {th }}$ edition, G. Thieme 1985 , p 250 .

12) Franzeck UK, Haselbach $P$, Speiser $D$, Bollinger A. Microangiopathy of cutaneous blood and lymphatic capillaries in chronic venous insufficiency (CVI). Yale J Biol Med. 1993 Jan-Feb; 66(1):37-46.

13) Allegra C, Carlizza A, Bartolo M jr. Lymphedema. Fluorescent Microlimphography. In Lee BB, Bergan J, Rockson SG (Editors). Lymphedema. 2011, Springer Ed. p. 191-8. ISBN 978-0-85729-566-8.

14) PhleboLymphedema. Vasculab Message Archive. DOI: 10.24019/2011.PhleboLymphedema - Msgs 4144-4221, Feb 6-20, 2011. https:/it.groups.yahoo.com/neo/groups/vasculab/conversations/ messages/4144 to 4221, Feb 6-20, 2011. Accessed on line on Mar 23, 2017. A (free) subscription is required. 